\title{
Genetic parameters for lactose and its correlation with other milk production traits and fitness traits in pasture-based production systems
}

\author{
M. Haile-Mariam*1 and J. E. Pryce*† \\ *Biosciences Research Division, Department of Economic Development, Jobs, Transport and Resources, Agribio, 5 Ring Road, \\ La Trobe University, Bundoora, VIC 3083, Australia \\ †School of Applied Systems Biology, La Trobe University, Bundoora, VIC 3083, Australia
}

\begin{abstract}
Lactose is a major component of milk (typically around $5 \%$ of composition) that is not usually directly considered in national genetic improvement programs of dairy cattle. Daily test-day lactose yields and percentage data from pasture-based seasonal calving herds in Australia were analyzed to assess if lactose content can be used for predicting fitness traits and if an additional benefit is achieved by including lactose yield in selecting for milk yield traits. Data on lactose percentage collected from 2007 to 2014, from about 600 herds, were used to estimated genetic parameters for lactose percentage and lactose yield and correlations with other milk yield traits, somatic cell count (SCC), calving interval (CIV), and survival. Daily test-day data were analyzed using bivariate random regression models. In addition, multi-trait models were also performed mainly to assess the value of lactose to predict fitness traits. The heritability of lactose percentage ( 0.25 to 0.37$)$ was higher than lactose yield (0.11 to 0.20$)$ in the first parity. Genetically, the correlation of lactose percentage with protein percentage varied from 0.3 at the beginning of lactation to -0.24 at the end of the lactation in the first parity. Similar patterns in genetic correlations were also observed in the second and third parity. At all levels (i.e., genetic, permanent environmental, and residual), the correlation between milk yield and lactose yield was close to 1 . The genetic and permanent environmental correlations between lactose percentage and SCC were stronger in the second and third parity and toward the end of the lactation $(-0.35$ to -0.50$)$ when SCC levels are at their maximum. The genetic correlation between lactose percentage in the first $120 \mathrm{~d}$ and CIV $(-0.23)$ was similar to correlation of CIV with protein percentage $(-0.28)$, another component trait with the potential to predict fertility. Furthermore,
\end{abstract}

Received September 1, 2016.

Accepted January 19, 2017.

${ }^{1}$ Corresponding author: Mekonnen.HaileMariam@ecodev.vic.gov.au the correlations of estimated breeding values of lactose percentage and estimated breeding values of traits such as survival, fertility, SCC, and angularity suggest that the value of lactose percentage as a predictor of fitness traits is weak. The results also suggest that including lactose yield as a trait into the breeding objective is of limited value due to the high positive genetic correlation between lactose yield and protein yield, the trait highly emphasized in Australia. However, recording lactose percentage as part of the routine milk recording system will enable the Australian dairy industry to respond quickly to any future changes and market signals.

Key words: lactose, fitness trait, genetic parameters and correlations

\section{INTRODUCTION}

Lactose is a major component of milk that is not directly considered in genetic improvement of dairy cattle in many countries (Sneddon, 2016). A few studies have explored whether lactose percentage can be used as a predictor of fitness traits (e.g., Reist et al., 2002; Buckley et al., 2003; Francisco et al., 2003), or as an additional yield trait to be included in the breeding objective in dairy cattle selection schemes (Sneddon et al., 2013; Berry, 2015). Reist et al. (2002) showed that the ratio of fat to lactose percentage was one of the most informative traits for precise estimation of energy balance in large dairy herds. Milk lactose concentration has been shown to be associated with resumption of luteal function in second-parity Norwegian dairy cattle (Reksen et al., 2002). In the Irish pasture-based dairy production system, Buckley et al. (2003) observed that a higher lactose percentage was associated with an increase in pregnancy rate, which means that the level of lactose could be a useful tool for identifying cows at risk of poor reproduction. Furthermore, lactose percentage has a moderate genetic correlation with SCC and can be used with SCS for genetic evaluation of udder health (Park et al., 2007; Ptak and Bieniek, 2012). Lactose content of milk from cows with mastitis 
is significantly lower than that from healthy cows and thus changes in lactose content over the lactation can be used as a predictor of mastitis incidence (Park et al., 2007). Miglior et al. (2006) also found that cows with low lactose percentages were more likely to be culled than cows with a high lactose percentage, suggesting that it can potentially be used as indicator of longevity. Lactose percentage is a less variable milk component than fat or protein percentage (e.g., Miglior et al., 2007; Ptak and Bieniek, 2012); thus, any unexpected change in lactose content could be associated with negative energy balance or other conditions of poor health. This means lactose content may be a more reliable measure for monitoring the health and well-being of dairy cows.

There is also interest in the possibility of selecting for lactose yield and percentage in some dairy production systems, especially where whole milk powder (WMP) is a large component of the dairy manufacturing industry (Sneddon, 2016). In New Zealand, where a large part of the milk produced is exported as WMP, a large deficit is present in milk lactose that is currently filled by importing lactose (Sneddon, 2016). After reviewing milk payment systems in 7 countries including New Zealand, Sneddon et al. (2013) found some form of indirect payment system for lactose yield only in the United States and Ireland. Sneddon et al. (2013) also called for a revision of the milk payment system in New Zealand, which is currently largely based on protein and fat yield with penalty on milk volume, to one based on protein, fat, and lactose yield with a penalty on volume. Although there does not appear to have been a change to the milk payment system in New Zealand since then, the negative price for milk has been replaced by a positive payment for lactose yield in the Netherlands (CRV, 2017). In New Zealand, as a part of the effort to include lactose in the breeding objective, Sneddon et al. (2015) estimated genetic parameters for milk components including lactose using data from New Zealand herds on a lactation basis. With the exception of the work in New Zealand, most genetic parameter estimates for lactose in the literature (Welper and Freeman, 1992; Miglior et al., 2007; Ptak and Bieniek, 2012) are from herds in the Northern hemisphere, where mostly cows are kept indoors and fed TMR. Also, most of the genetic parameters that are available in literature, with few exceptions, are based on relatively small data sets using lactation data rather than test-day data.

Information on the genetic control of lactose content in Australian dairy cattle and its relationship with milk yield traits and other economic traits is lacking. It is also important to examine the genetic trend in lactose percentage as well as yield because the selection in Australia over the last 2 decades has been for increased protein and fat yield (Bowman et al., 1996), with nega- tive economic weight on milk volume a trait highly correlated with lactose yield (e.g., Miglior et al., 2007). The main objective of this study is to estimate genetic parameters for lactose content and its relationship with milk yield traits and SCC using a random regression (RR) model as a first step to assess if there is merit in developing genetic evaluation for lactose yield, or content, for Australian Holstein cattle. The secondary objective is to assess if lactose content can be used as an indicator of fertility, survival, and other predicators of fitness with the view to using it as a predictor trait. To do this, test-day data of cows that included lactose percentage in the first 3 parties were used.

\section{MATERIALS AND METHODS}

\section{Data}

Data on daily milk yield traits including lactose percentage and SCC of cows that calved between 2007 and 2014 were extracted from the Australian Dairy Herd Improvement Scheme (ADHIS) database. First, cows that are the progeny of bulls in the AI program with at least 5 daughters were kept. From these data, cows that had at least 1 test-day lactose percentage in the first $120 \mathrm{~d}$ were selected. The age at first calving for the animals selected for this study varied from 18 to 36 mo. Based on these criteria, close to 98,000 cows and all their test-day milk yield data recorded between d 1 and 315 DIM from 621 herds were selected. Most of the herds that provided these data were from the Eastern Victoria Region of Australia, where pasture-based seasonal calving systems dominate. Most of the cows with lactose percentage were Holstein (75\%), Jersey (10\%), and their cross-breeds. The number of tests, cows and mean daily milk, mean daily lactose percentage, and mean protein percentage in the first 3 parities is presented in Table 1. From these data, cows with at least 3 test-day lactose percentage records in the first parity that were born before January 2011 (i.e., cows with opportunity to calve for the second and third time) were selected for genetic parameter estimation.

\section{Statistical Analyses}

The analyses in this study included estimation of the relationship of lactose percentage and yield with milk yield, $\log$ (natural $\log$ ) SCC $\left(\log _{\mathrm{e}} \mathrm{SCC}\right)$, fat, and protein percentage in the first, second, and third parity using a RR model. All the analyses that looked at the relationship between traits used within parity data except those carried out to estimate heritability of lactose percentage over the course of the first 3 lactations and the relationships between lactose percentage in the first 
parity with lactose in the second and third parity where analyses of 2 parity data were performed.

All data analyses were carried out using ASReml (Gilmour et al., 2009). The first class or test record consisted of tests that were measured between 4 and 36 $\mathrm{d}$ from calving; subsequent test records were at intervals of $30 \mathrm{~d}$, with the exception of the tenth test interval, which was a period of $40 \mathrm{~d}$. Due to software restrictions in the modeling of the error variance, cows were not allowed to have more than one test record in a particular interval $(\sim 30 \mathrm{~d})$; this was done by restricting the test data to the first observation within the interval. As a result, about $5 \%$ of the records were deleted. Only $51 \%$ of the cows had valid lactose test-day records in the first month (4 to $36 \mathrm{~d}$ ), which increased to $58 \%$ in the second test and dropped to about $45 \%$ in the last test interval ( 275 to $315 \mathrm{~d}$ ). Overall, of the test-dates with valid milk yield data, about $26 \%$ of them did not have lactose percentage (Table 1 ).

The basic model used for analyses, which is a bivariate RR model, is given below in matrix notation:

$$
\mathbf{y}_{\mathrm{T}}=\mathbf{X}_{\mathrm{T}} \mathbf{b}_{\mathrm{T}}+\mathbf{Z}_{\mathrm{T}} \mathbf{a}_{\mathbf{T}}+\mathbf{W}_{\mathrm{T}} \mathbf{p}_{\mathrm{T}}+\mathbf{e}_{\mathrm{T}},
$$

where $\mathbf{y}_{\mathbf{T}}$ is the observation on 2 traits (i.e., generally lactose percentage and one of the other milk yield or component traits or $\left.\log _{\mathrm{e}} \mathrm{SCC}\right), \mathbf{X}_{\mathrm{T}}$ is the incidence matrix for fixed effects [herd-test date, year-season of calving (2 seasons each year), age at calving in months (polynomial order of 2), DIM (polynomial order of 6), breed group of cow], $\mathbf{b}_{\mathrm{T}}$ is the vector of all fixed effects, $\mathbf{Z}_{\mathbf{T}}$ is incidence matrix for random effects of animal, $a_{T}$ is vector of RR (Legendre polynomial order of 3 of DIM) animal genetic effect, $\mathbf{W}_{\mathbf{T}}$ is the incidence matrix for random permanent environmental effect, $\mathbf{p}_{\mathbf{T}}$ is the vector of RR (Legendre polynomial order of 3 of DIM) permanent environmental effects, and $\mathbf{e}_{\mathrm{T}}$ the vector of random residual effects assumed to have the same (ho- mogeneous) variance within a test period $(\sim 30 \mathrm{~d})$ but allowed to vary across test periods.

The expectations are $\mathbf{E}\left(\mathbf{y}_{\mathbf{T}}\right)=\mathbf{X}_{\mathbf{T}} \mathbf{b}_{\mathbf{T}}, \mathbf{E}\left(\mathbf{a}_{\mathbf{T}}\right)=0$, $\mathrm{E}\left(\mathrm{p}_{\mathrm{T}}\right)=0, \mathrm{E}\left(\mathrm{e}_{\mathrm{T}}\right)=0$ with the following variancecovariance matrix:

$$
\operatorname{Var}\left(\mathbf{a}_{\mathbf{T}}\right)=\mathbf{G} \otimes \mathbf{A}_{\mathbf{a}}, \operatorname{Var}\left(\mathbf{p}_{\mathbf{T}}\right)=\mathbf{P} \otimes \mathbf{I}_{\mathbf{c}}, \operatorname{Var}\left(\mathbf{e}_{\mathbf{T}}\right)=\mathbf{R} \otimes \mathbf{I}_{\mathbf{e}},
$$

where $\mathbf{G}$ and $\mathbf{P}$ are genetic and permanent environmental variance-covariance matrices, respectively, of size 6 [2 traits $\times$ (intercept, linear, and quadratic $\mathrm{RR}$ )]; $\mathbf{R}$ is the heterogeneous residual variance-covariance matrix of $10 \times 2$ block diagonal matrices for each testday ( $\sim 30$-d intervals) when analyzing 2 different traits recorded at the same time, or a diagonal matrix of size 20, where the first 10 are for 1 parity and the second 10 are for next parity data; $\mathbf{A}_{\mathbf{a}}$ is the matrix of additive genetic relationships among animals, and $\mathbf{I}_{\mathbf{c}}$ is an identity matrix of permanent environmental effects of cows with test-day data, $\mathbf{I}_{\mathbf{e}}$ is an identity matrix for each test-day record, $\otimes$ is the Kronecker product. The $\mathbf{A}_{\mathbf{a}}$ matrix was constructed using all the available pedigree information on all animals and was traced back to ancestors born in the 1950s. Animals with unknown parents were grouped based on their birth year, country of origin, and sex according to standard ADHIS genetic evaluation procedures (ADHIS, 2004).

To verify the results from the RR models and gauge standard errors of estimates we also performed multitrait analyses, where yield traits recorded on different test-days were treated as separate traits using data from the first and second parity. These analyses concentrated on lactose and fat yield because the RR analyses showed that the genetic correlation between them changed over the course of the lactation more than the correlation for the other traits. We used 2 traits (lactose and fat yield) and 5 time intervals (i.e., the first, second, sixth, ninth, and tenth test) in these analyses. The fixed effects fit-

Table 1. Description of the test-day data used in the analysis over the first 3 lactations

\begin{tabular}{lcrr}
\hline & \multicolumn{2}{c}{ Lactation } \\
\cline { 2 - 4 } Item & First & Second & Third \\
\cline { 2 - 4 } & $388,893(528,558)^{1}$ & $217,384(307,919)^{1}$ & $118,048(172,926)^{1}$ \\
Total no. of tests & 604 & 537 & 502 \\
No. of herds & $97,342(44,740)^{2}$ & $59,717(35,467)^{2}$ & $34,933(20,990)^{2}$ \\
Total no. of cows & 3,799 & 3,105 & 3,060 \\
No. of sires & $5.03(0.21)^{3}$ & $4.97(0.20)^{3}$ & $4.94(0.20)^{3}$ \\
Mean test-day lactose (\%) & $3.38(0.35)^{3}$ & $3.43(0.39)^{3}$ & $3.42(0.39)^{3}$ \\
Mean test-day protein (\%) & $21.43(6.88)^{3}$ & $24.97(8.74)^{3}$ & $26.54(9.38)^{3}$ \\
Mean test-day milk yield (L) & $153.3(86.2)^{3}$ & $153.1(86.1)^{3}$ & $152.9(86.0)^{3}$ \\
Mean DIM & & \\
${ }^{3}$ No. of tests with valid milk yield in parentheses. & \\
${ }^{2}$ No of cows used for genetic parameters in each lactation in parentheses. & \\
${ }^{3}$ Standard deviation in parentheses.
\end{tabular}


ted were the same as those used in the RR models, but animal was the only random effect fitted in this case. Bivariate-2-test-period model analyses that included lactose and fat yield were run. These produced a $4 \times$ 4 animal genetics variance-covariance matrix and an equivalent-sized residual matrix.

The secondary objective of this study was to see if lactose percentage (e.g., Buckley et al., 2003), or the ratio of fat to lactose percentage, or change in lactose percentage (Reist et al., 2002) can be used as indicator of fertility or other functional traits. For this, the first test-day lactose percentage or fat to lactose ratio that is recorded in the first 120 DIM was analyzed with calving interval (CIV) or survival of cows to estimate the genetic correlation (i.e., lactose or fat to lactose ratio with CIV). These analyses were restricted to data of first parity only as the number of cows with both lactose percentage and fitness data in second and subsequent parities was small. The change in lactose percentage from the first to the second recorded test in the first $120 \mathrm{~d}$ of lactation was also correlated with CIV or survival. These analyses were a series of bivariate analyses, fitting the appropriate fixed (DIM, herd testdate, year-season of calving for lactose percentage, and herd-year-season of calving for CIV and survival) and random effects of animal for both traits as described above. Age at calving, month of calving, and breed group were also fitted as fixed effects for both traits. Details about the CIV and survival data are described elsewhere (e.g., Haile-Mariam et al., 2013). Briefly, CIV between 290 and $762 \mathrm{~d}$ were considered valid and survival was coded as survived (1) if the cow re-calved or culled (0). Cows with no CIV or whose survival status is unknown were included in the analyses with missing data. In addition, we also estimated the correlation of protein percentage with CIV and survival to assess if lactose percentage is better than protein percentage for predicting fitness traits because analyses of Australian data showed that protein percentage early in lactation is strongly associated with fertility traits (Morton et al., 2016).

Genetic parameters for milk yield traits including lactose yield were estimated using multi-trait models on a lactation basis for the first, second, and third parity separately. This was done to investigate the consequences of positive selection for protein and fat yield with a negative economic value $(\mathbf{E V})$ on milk volume that has occurred in Australia over the last 20 yr (Bowman et al., 1996) on lactose yield and to assess the benefit of including lactose yield in the breeding objective. For these analyses, test-days within lactation were considered as repeated records. The effect of selection with a negative EV for milk volume on lactose were calculated using parameters from the first parity assuming a 4-pathway breeding scheme, where the rate of genetic gain over a 10-yr period is assumed (Lush, 1945).

In all cases, for simplicity, it was assumed that only milk production traits were included in the breeding objective. This is equivalent to selection on the production (sub)index available in Australia through the ADHIS, which is known as the Australian Selection Index (ASI, which is expressed in Australian \$) and modifications of this index to include lactose. The EV applied to EBV for milk yield, fat yield, and protein yield in the ASI are $-\$ 0.1, \$ 1.79$, and $\$ 6.92$, respectively (e.g., Byrne et al., 2016). We tested 2 other scenarios (1) where the EV for milk volume was set to $\$ 0$ instead of $-\$ 0.1$, and (2) where the EV applied to lactose was arbitrarily set to $\$ 1.0$ while keeping EV for milk volume at $-\$ 0.1$.

Finally, EBV for lactose percentage and yield were estimated using an animal model BLUP, assuming the genetic parameters that were estimated were the true values. Then the resulting EBV were correlated with published EBV for survival, fertility, SCC, and angularity (traits considered to be measures of robustness) for sires with at least 5 progeny with lactose percentage. The EBV for survival, fertility, SCC, and angularity were obtained from the official genetic evaluations released by ADHIS in August 2015.

\section{RESULTS}

\section{Mean Performance}

The mean daily lactose percentage in first, second, and third parities are shown in Table 1. Figure 1 shows that the daily mean lactose percentage in the first parity is slightly higher than in the second and third lactation. The lactation curve for lactose percentage is similar to that of milk yield with the highest percentage value occurring at about peak yield (DIM of 30 to 40 d), in contrast to protein percentage, which is the lowest at about peak yield in almost all the 3 lactations. This means lactose percentage, unlike protein and fat percentage, is not affected by dilution.

\section{Genetic Parameters for Lactose Percentage and Yield}

Figure 2 shows the heritability of lactose percentage and lactose yield across lactation in the first 3 parities. Both lactose percentage and yield are more heritable in mid-lactation compared with early lactation. In the second and third parities, the heritability of both lactose percentage and yield increased toward the end of lactation, mainly due to a decrease in the residual variance without reduction in animal genetic variance 
(data not shown). Overall, the heritability of lactose yield is lower than the lactose percentage, as expected.

Figure 3 shows the genetic and permanent environmental correlations of lactose percentage on d 15 of lactation with the rest of the lactation in parities 1,2 , and 3 (i.e., within parity). In all parities, the genetic correlations gradually decrease to as low as 0.7 by the end of the lactation. The trend in permanent environmental correlations, which is similar for all 3 parities, showed a gradual decline with stage of lactation until about $200 \mathrm{~d}$ and then increased again toward the end of the lactation (Figure 3).

Genetic correlations on the same day between lactose percentage in the first and second parity (data not shown) were higher (0.91 to 0.97 ) than between parity 1 and 3 (0.84 to 0.96). They were also high between parity 2 and 3 . However, permanent environmental correlations between parity 1 and 2 were lower $(0.39$ to 0.63$)$ than genetic correlations and also the correlations between parity 1 and 3 varied from 0.19 to 0.52 when measured on the same DIM. Both the genetic and permanent environmental correlations between parities were lowest at the end of the lactation and highest at about the third to fourth months of lactation (data not shown).
Relationship of Lactose Percentage or Yield with $\log _{e}$ SCC and Yield and Component Traits. The genetic, permanent environmental, and residual correlations between lactose yield and milk yield were very high (all above 0.96) when both traits are measured on the same DIM and parity (data not shown). On the other hand, for lactose percentage, the genetic, permanent environmental, and residual correlation with milk yield is near zero $(-0.25$ to 0.31$)$ in the first and third parity. In early second parity, the genetic correlations were slightly more unfavorable $(-0.43$ at DIM of 15) than in the first or third lactation (data not shown). Regardless of the lactation stage, or parity, all correlations (genetic, permanent environmental and residual) between fat percentage and lactose percentage were near zero ( -0.20 to 0.22$)$. All the correlations (genetic, permanent environmental, and residual) between lactose percentage and the ratio of fat to protein yield were even closer to zero than those between lactose percentage and fat percentage (results not presented elsewhere).

Lactose percentage is more unfavorably correlated (genetic, permanent environmental, residual) with $\log _{\mathrm{e}}$ SCC over the first 3 parities compared with other traits considered in this study (Figure 4). The genetic

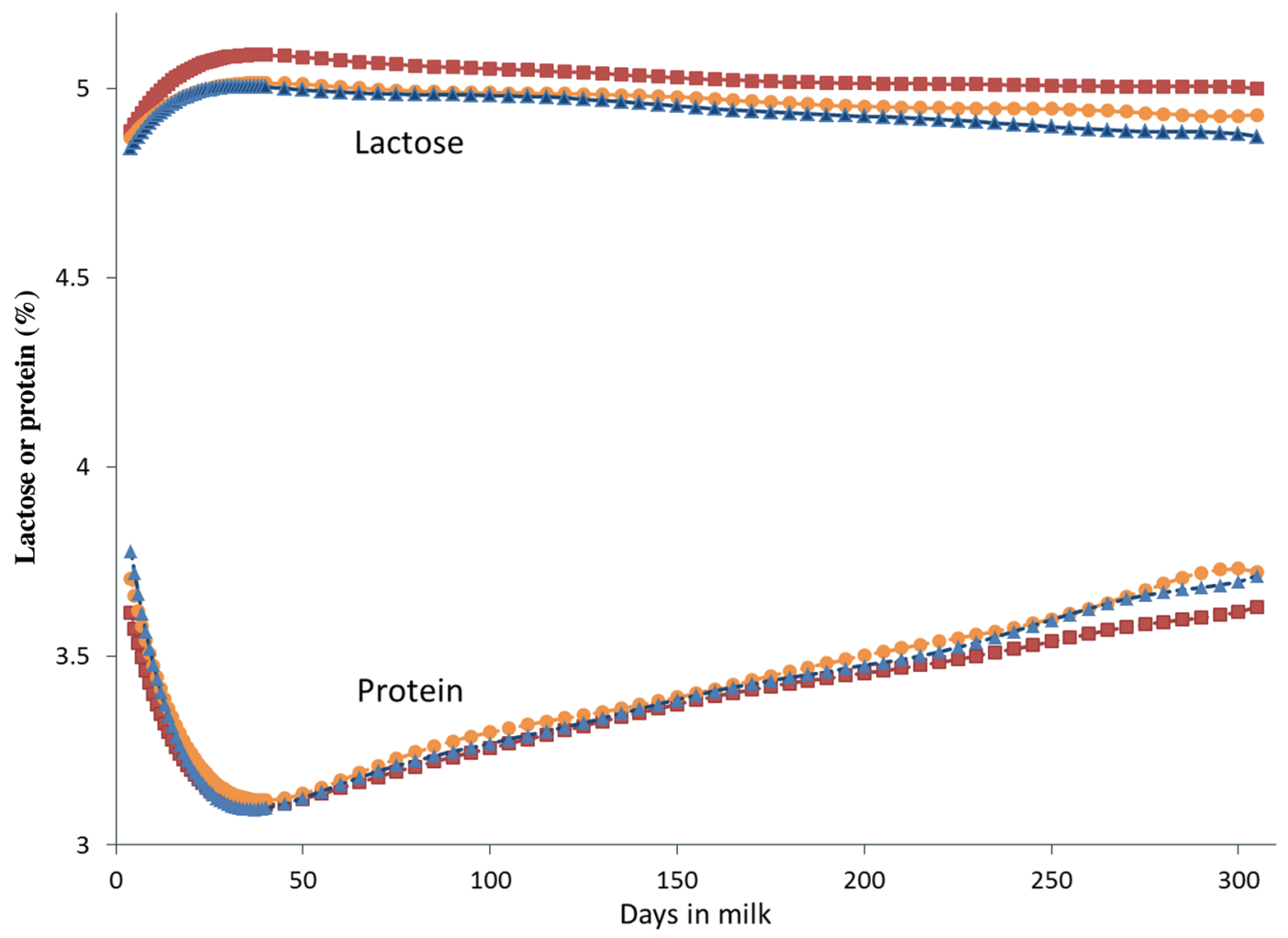

Figure 1. Lactose percentage (solid line) and protein percentage (dashed line) in first, second, and third parity cows tively). Color version available online. 


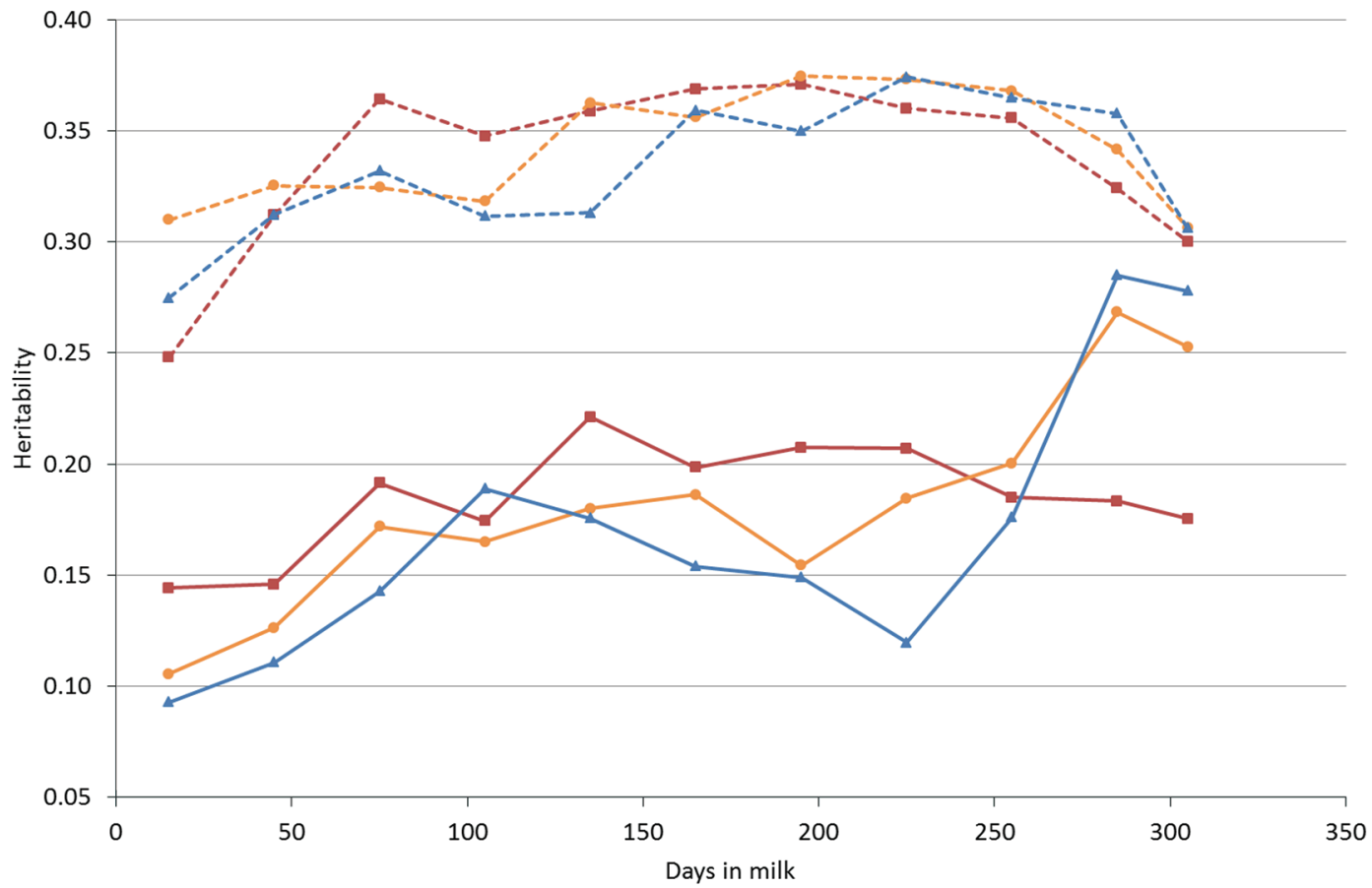

Figure 2. Heritability of lactose percentage (dashed line) and yield (solid line) in first, second, and third parity cows tively). Color version available online.

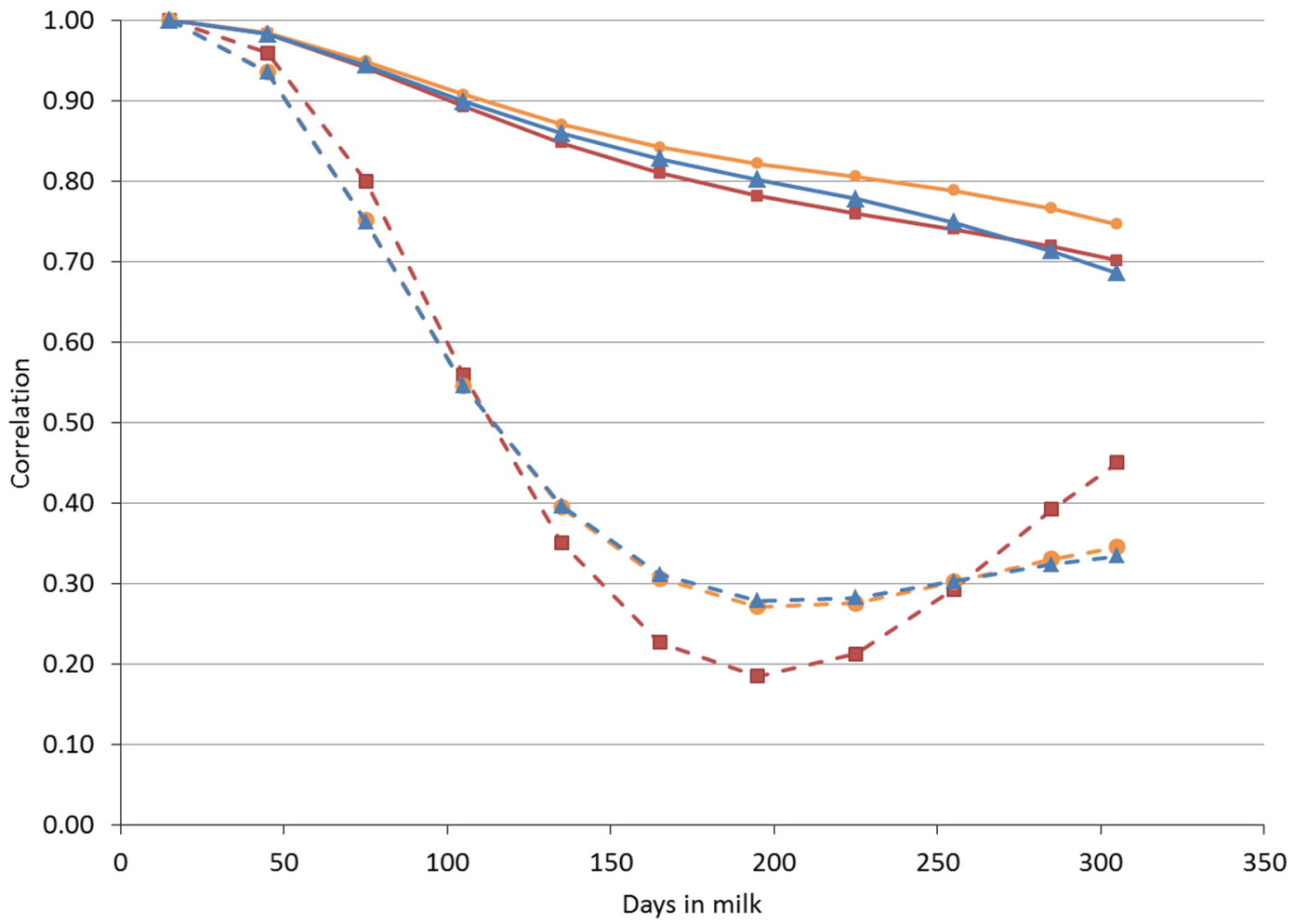

Figure 3. Genetic (solid line) and permanent environmental (dashed line) correlations of lactose percentage on d 15 of lactation with the rest of the lactation periods in first, second, and third parity cows $(\mathbf{\square}, \boldsymbol{\bullet}$, and $\boldsymbol{\Lambda}$, respectively). Color version available online. 


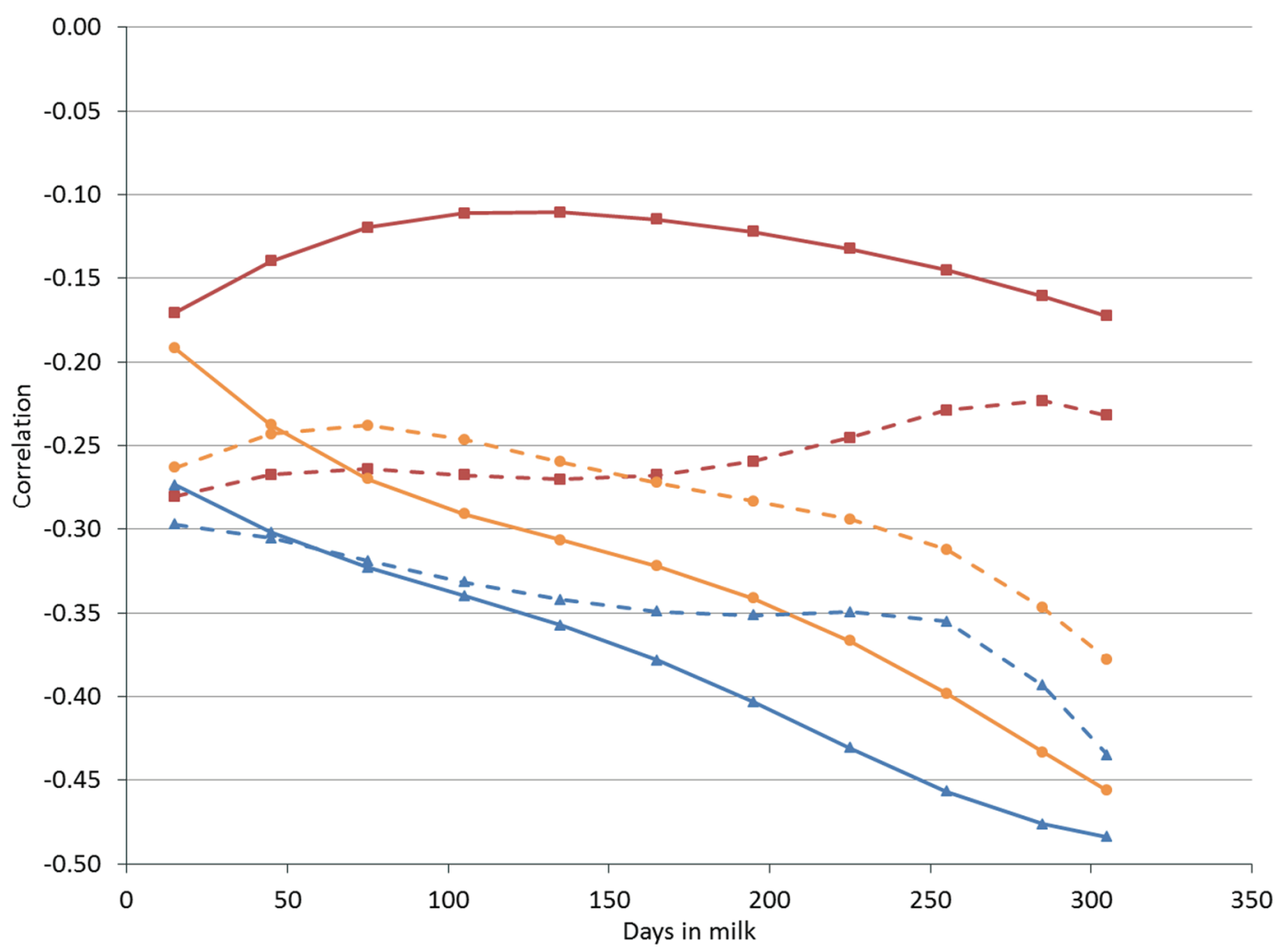

Figure 4. Genetic (solid line) and permanent environmental (dashed line) correlations of lactose percentage and SCC in first, second, and third parity cows $(\mathbf{\square}, \boldsymbol{\bullet}$, and $\boldsymbol{\Lambda}$, respectively). Color version available online.

and permanent environmental correlations in the first 3 lactations observed on the same DIM are shown in Figure 4. Consistent with the genetic and permanent environmental correlations, the strength of the residual correlations also increased with parity. The residual correlations, however, varied within a narrow range and were -0.14 to -0.18 in the first lactations, -0.15 to -0.21 in the second parity, and -0.18 to -0.25 in the third parity, so these are not presented elsewhere.

Figure 5 shows that the genetic correlation between lactose percentage and protein percentage is positive (i.e., $\sim 0.3$ or above) at the beginning of the lactation in the first 3 parities and negative $(\sim-0.1$ to -0.24$)$ at the end of the lactation when observed on the same DIM. Both the permanent environmental correlations (Figure 5) and residual correlations were positive (0.03 to 0.26$)$.

Table 2 shows the residual environmental and genetic correlation among milk yield traits including lactose yield on a lactation basis in the first 3 parities. The results in Table 2, in which the genetic correlation between milk yield and lactose yield are consistently close to 1.0, agree with the results from the RR models. Overall, the correlations of other yield traits with lactose yield are higher than 0.7, except the genetic correlation with fat yield, which are below 0.34 on a lactation basis. However, as demonstrated in Figure 6 (from RR analyses) and Table 3 (from multi-trait analyses), the genetic correlation between lactose yield and fat yield varied over the lactation. These correlations are moderately high at the beginning and end of the lactation and at their lowest level in the middle of the lactation. On the other hand, permanent environmental correlations and residual correlations varied within a narrower range when compared with genetic correlations. These change in genetic correlation between lactose and fat yield over the lactation were in line with those observed in lactose percentage and fat percentage, which ranged from 0.18 (beginning of lactation) to -0.20 (end of lactation) of the first parity. In the second parity, the genetic correlations were positive $(\sim 0.20)$ early in the lactation and negative or zero at the end of the lactation (Figure 6).

Relationship of Lactose Percentage with CIV, Survival, and Other Indicators of Functionality. The genetic correlation of lactose percentage and other measures derived from lactose percentage with CIV and survival is small (Table 4). Table 4 also includes the genetic correlation of CIV and survival with protein percentage for comparison purposes. The correlations of lactose yield and lactose percentage EBV with EBV 


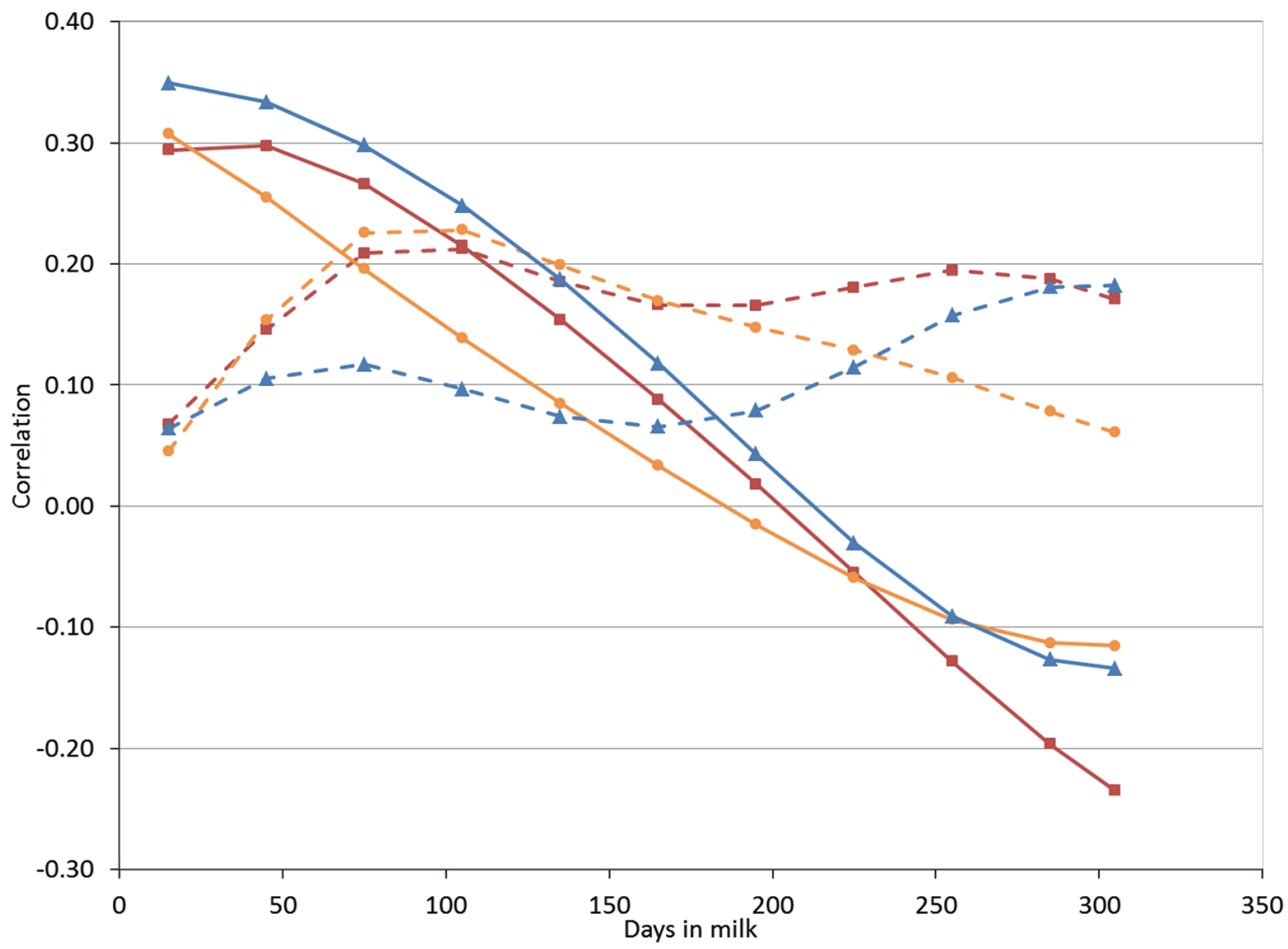

Figure 5. Genetic (solid line) and permanent environmental (dashed line) correlations of lactose and protein percentage within first, second, and third parity cows $(\boldsymbol{\square}, \bullet$, and $\boldsymbol{\Lambda}$, respectively). Color version available online.

for survival, angularity, 6-wk in-calf rate, SCC, and milk yield based on about 1,000 bulls that are shown in Table 5 are also low. However, as expected, all the correlations support that lactose percentage can be used as a possible indicator of fitness traits.

Consequences of Selection with a Negative $\boldsymbol{E V}$ on Milk Volume on Lactose. Genetic response over $10 \mathrm{yr}$ of selection based on the current selection practice of putting a negative EV on milk volume $(-\$ 0.1)$ compared with $\$ 0 \mathrm{EV}$ and putting a $\$ 1.0 \mathrm{EV}$ on lactose yield is shown in Figure 7. Putting a negative EV on milk volume means that only 79 and $69 \%$ of the possible genetic response was achievable in milk and lactose yield, respectively, compared with $\$ 0$. Figure 7 shows that removing the negative $\mathrm{EV}$ on milk volume increased genetic responses by 6,45 , and $27 \%$ for protein, lactose, and milk yield, respectively, and reduced that of fat yield by $3 \%$ over a $10-y r$ selection period. The reduction in fat yield happens because of the low genetic correlation $(\sim 0.3)$ between fat and lactose yield. A greater genetic response in lactose yield could be achieved by removing the negative economic weight on milk volume, although this comes at the expense of increasing milk (and consequently the cost of transportation). If the interest is to achieve more response in lactose yield, removing the negative $\mathrm{EV}$ on milk volume is more effective than increasing the $\mathrm{EV}$ of lactose up to $\$ 1.5$ per kilogram.

Over a 10-yr period of selection, genetic progress in milk and lactose yield will slow due to the negative weight on milk volume, and this, we have estimated using correlations between breeding values, will mean that lactose percentage will decrease from 4.81 to $4.78 \%$. This is a small change, and at this stage there is little evidence of a long-term disadvantage of selection for milk yield traits with a negative economic weight for milk volume, instead of selecting for lactose yield. Looking at the mean EBV for lactose percentage over the last 10 yr (1999-2008), a positive but nonsignificant genetic trend for lactose percentage is observed.

\section{DISCUSSION}

The mean daily lactose percentage in this data set is higher than most estimates in the literature (Welper and Freeman, 1992; Miglior et al., 2007; Stoop et al., 2007; Ptak and Bieniek, 2012) with the exception of those from New Zealand (Sneddon et al., 2015), which were reported to be $5.12 \%$ in first parity cows, which may suggest that the mean lactose percentage in sea- 


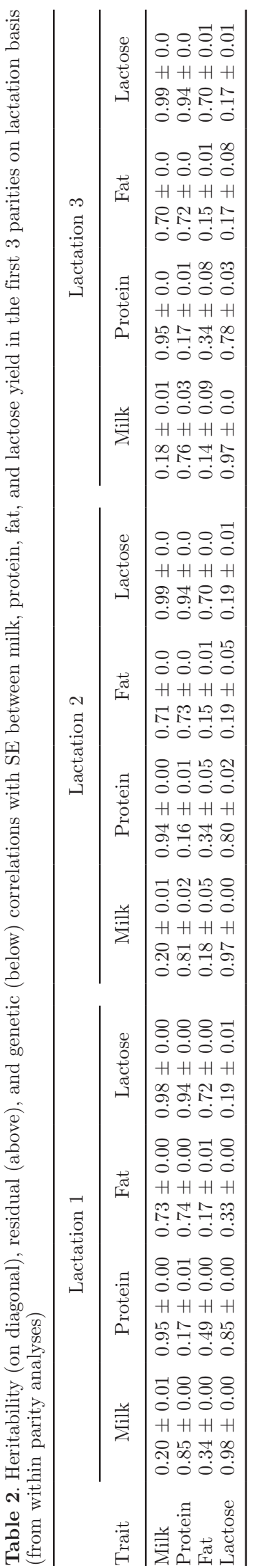

sonal calving herds is higher than nonpasture farming systems. However, a review by Sneddon (2016) did not find evidence to suggest that lactose percentage in pasture fed cows is actually higher than TMR-fed cows. The coefficient of variation of lactose percentage (4.0 to $4.2 \%$ ) is lower compared with components like protein percentage (10.4 to $11.4 \%$ ), which is in agreement to other reports (Miglior et al., 2007; Stoop et al., 2007). The mean test-day milk yield of cows used in this study (Table 1) is slightly lower than those reported by Haile-Mariam and Goddard (2008), where most of the cows in that study were from high-producing herds compared with the cows in this study which are from pasture-based seasonal calving herds, so the high lactose percentage observed in this study may not be representative of average Australian herds.

The lactation curve for lactose percentage in Figure 1 is similar to that reported by Ptak and Bieniek (2012) who observed similar trends in Polish Holstein-Friesians in first lactation and older cows. The observation that lactose percentage decreased with increasing lactation number agrees with the observations of Miglior et al. (2007) and Ptak and Bieniek (2012). The high lactose percentage in the first relative to that in second and later parities is perhaps a reflection of the high persistency of milk yield in the first parity.

Heritability estimates for lactose percentage and yield are lower than most other studies (Welper and Freeman, 1992; Miglior et al., 2007; Stoop et al., 2007), which is in agreement with the observation that heritability estimates for milk yield traits estimated using Australian data are generally lower than those from many European and North American populations. However, our estimates are higher than those for Polish (Ptak and Bieniek, 2012) and New Zealand cows (Sneddon et al., 2015), where the mean milk production levels were lower than those observed in Australia. Within Australia, daily heritability estimates for milk yield were higher ( 0.22 to 0.34$)$ in high production herds (Haile-Mariam and Goddard, 2008) than those presented in the current study, which varied from 0.19 to 0.27 . However, the pattern of heritability over the lactation and across parities observed in this study are in general similar to those observed by others (Miglior et al., 2007).

The high correlations between lactose yield and milk yield is consistent with those reported by Miglior et al. (2007) and Sneddon et al. (2015). Our results of the genetic correlation between fat yield and lactose yield are different from those quoted (0.79 and 0.81) in Sneddon (2016), but are closer to the estimate (0.40) based on New Zealand data reported by Sneddon et al. (2015). In the current study, the genetic correlation between lactose yield and fat yield changed over lactation 
Table 3. Genetic and residual correlation with SE between lactose yield and fat yield on selected tests in first and second parity cows

\begin{tabular}{lccccc}
\hline & \multicolumn{2}{c}{ Parity 1} & & \multicolumn{2}{c}{ Parity 2} \\
\cline { 2 - 3 } \cline { 5 - 6 } Test & Genetic & Residual & & Genetic & Residual \\
\hline $1(4-36$ DIM $)$ & $0.61 \pm 0.05$ & $0.78 \pm 0.01$ & & $0.50 \pm 0.10$ & $0.72 \pm 0.01$ \\
$2(37-66$ DIM $)$ & $0.33 \pm 0.06$ & $0.75 \pm 0.01$ & & $0.22 \pm 0.10$ & $0.68 \pm 0.01$ \\
$6(157-186$ DIM $)$ & $0.23 \pm 0.06$ & $0.72 \pm 0.01$ & & $0.25 \pm 0.09$ & $0.68 \pm 0.01$ \\
$9(247-276$ DIM $)$ & $0.31 \pm 0.06$ & $0.76 \pm 0.01$ & & $0.49 \pm 0.08$ & $0.81 \pm 0.01$ \\
$10(277-315$ DIM $)$ & $0.43 \pm 0.06$ & $0.77 \pm 0.01$ & & $0.47 \pm 0.11$ & $0.81 \pm 0.01$ \\
\hline
\end{tabular}

because of a change in fat yield rather than a change in lactose yield as lactation progresses (Figure 6 and Table 3). The genetic correlation between fat yield and milk yield also shows a similar trend, suggesting that the somewhat tight link between the 2 yield traits at the beginning and end of the lactation (0.55) becomes loose in the middle of the lactation in both the first and second parity where the genetic correlations were about 0.11 to 0.22 at 165 DIM. The reasons for the observed change in genetic correlation of fat yield with lactose or milk yield could perhaps be related to the change in fatty acids that make up fat yield over the lactation (Stoop et al., 2008, 2009).

The relationship of lactose percentage with $\log _{e}$ SCC is stronger in later parities, as well as between early and late lactation in the first lactation when the level of SCC is higher; this observation is in agreement with other findings (Park et al., 2007; Miglior et al., 2007). When SCC levels are higher than normal, the role of lactose as a determinant of rate of water secretion is disrupted, which results in reduced lactose percentage (Shuster et al., 1991; Auldist et al., 1995). Also an increase in SCC is a possible indicator of mastitis because the leakage rate of lactose out of the alveolus may increase (Shuster et al., 1991; Harmon 1994; Auldist et al., 1995), resulting in a reduced lactose content in milk. Currently, in several countries including Australia, SCC is used for selection to improve udder health; it will be useful to assess if joint analyses of SCC and lactose percentage can improve genetic evaluations for udder health as suggested by Park et al. (2007) and Ptak and Bieniek (2012).

Several studies (Reist et al., 2002; Buckley et al., 2003; Francisco et al., 2003) at the phenotypic level found that lactose percentage, or the ratio of fat to lactose, are associated with fertility traits. In this study, at the genetic level, the correlation estimates from variance co-variance analyses between CIV and lactose percentage were stronger than the approximate genetic correlation between EBV for lactose and fertility. Nearzero correlations between EBV for lactose percentage and fertility were also observed in Canadian Holsteins (Miglior et al., 2007). The correlations between EBV for lactose percentage and SCC in Table 4 are similar to those reported by Miglior et al. (2007). Both the positive genetic and residual correlation between survival and lactose percentage observed in this study were in agreement with Miglior et al. (2006). Overall, the fact that the value of lactose percentage for predicting fitness is negligible agrees with the finding of Miglior et al. (2007) in Canadian dairy cattle. However, further detailed investigation may still be useful because the number of cows with lactose and fitness data in the current and other studies is limited and also correlations between EBV may be biased downward.

Since the early 1990s, selection for milk yield traits in Australia has emphasized protein yield and to a lesser extent fat yield, with a negative weight on milk volume (Bowman et al., 1996), which is consistent with countries such as New Zealand. A negative weight on

Table 4. Genetic and residual correlations with SE of lactose percentage, fat-to-lactose ratio, fat-to-protein ratio, and protein percentage at the first recorded tests with calving interval and survival

\begin{tabular}{|c|c|c|c|c|}
\hline \multirow[b]{2}{*}{ Trait } & \multicolumn{2}{|c|}{ Calving interval } & \multicolumn{2}{|c|}{ Survival } \\
\hline & Genetic & Residual & Genetic & Residual \\
\hline Lactose $(\%)$ & $-0.23 \pm 0.07$ & $-0.03 \pm 0.01$ & $0.17 \pm 0.07$ & $0.04 \pm 0.00$ \\
\hline Fat-to-lactose ratio & $-0.08 \pm 0.06$ & $-0.01 \pm 0.00$ & $0.05 \pm 0.06$ & $0.01 \pm 0.01$ \\
\hline Fat-to-protein ratio & $0.06 \pm 0.04$ & $0.01 \pm 0.0$ & $-0.02 \pm 0.04$ & $-0.00 \pm 0.01$ \\
\hline Protein $(\%)$ & $-0.28 \pm 0.04$ & $-0.06 \pm 0.0$ & $0.12 \pm 0.03$ & $0.01 \pm 0.00$ \\
\hline Change in lactose ${ }^{1}(\%)$ & $0.02 \pm 0.13$ & $-0.01 \pm 0.01$ & $-0.02 \pm 0.11$ & $0.01 \pm 0.01$ \\
\hline
\end{tabular}

${ }^{1}$ First test-day to second test-day. 


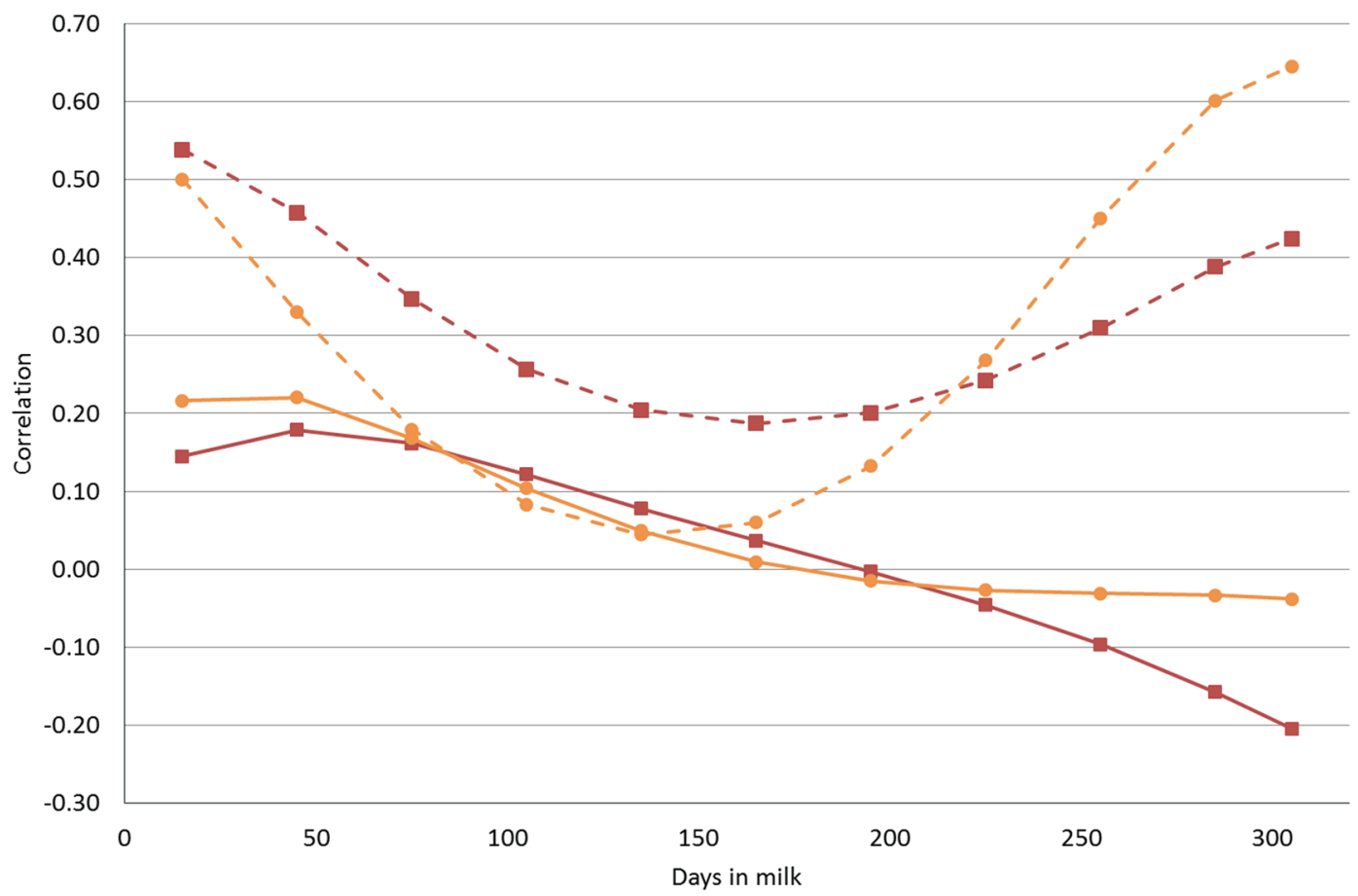

Figure 6. Genetic correlation between lactose yield and fat yield (dashed line) and lactose percentage and fat percentage (solid line) in first and second parity cows ( $\boldsymbol{\square}$ and $\bullet$, respectively). Color version available online.

milk volume also implies a negative weight on lactose yield and percentage because of the strong correlation between milk volume and lactose traits. However, because lactose is a source of energy, there may not be justification to decrease its content in milk. In the absence of clear market signals, this could be achieved by removing the negative economic weight on milk volume. This will increase cost of transporting, storing, and drying milk, which could be more expensive in large countries like Australia. Assuming the EV in ASI (i.e., $-\$ 0.1, \$ 6.92$, and $\$ 1.79$ for milk, protein, and fat, respectively), then the total economic response of

Table 5. Correlations between EBV for lactose percentage or yield and fitness traits (fertility, survival) and indicators of fitness traits (angularity, SCC, udder depth, pin width, and milk yield) obtained from routine national genetic evaluation

\begin{tabular}{lcc}
\hline Trait with EBV & $\begin{array}{c}\text { Lactose } \\
\text { percentage }\end{array}$ & $\begin{array}{c}\text { Lactose } \\
\text { yield }\end{array}$ \\
\hline Fertility & 0.08 & -0.27 \\
Overall survival & 0.07 & 0.08 \\
SCC & 0.15 & 0.0 \\
Angularity & -0.13 & 0.14 \\
Udder depth & 0.05 & -0.06 \\
Body depth & -0.05 & 0.03 \\
Pin set & 0.05 & 0.16 \\
Milk yield & 0.06 & $0.83^{1}$ \\
\hline
\end{tabular}

${ }^{1}$ Correlation of milk yield and lactose yield calculated from the same data for both traits was 0.96 .
$10 \mathrm{yr}$ of selection on the 3 indices tested (i.e., current, $\$ 0 \mathrm{EV}$ on milk volume and $\$ 1.0 \mathrm{EV}$ on lactose yield) were $\$ 70.87, \$ 69.84$, and $\$ 68.10$ for scenarios 1,2 , and 3 , respectively; thus, there is a small compromise per cow over 10 yr of selection (up to $\$ 2.77$ ) to including lactose in the breeding objective. These are calculated assuming no value for lactose and a future review of the economic index in Australia should consider the merit of placing EV on lactose yield itself.

In Australia, unlike in New Zealand, the proportion of milk processed into WMP is about $12 \%$ based on the latest figures and the trend is not increasing (Dairy Australia, 2016). Also, on average milk produced in Australia has less protein $(3.4 \%$, Table 1$)$ content compared with, for example, $3.8 \%$ in New Zealand (Sneddon et al., 2015). Thus, even if WMP was significant in the Australian processed milk market, the ratio of protein percentage to SNF percentage is close to 0.39 , which is the international standard level for WMP according to Geary et al. (2010). If, according to the modeling work of Sneddon (2016), markets arise for specialist products, then it may be valuable to develop customized breeding programs that include lactose in the breeding objective. However, the limitation with this is that milk processors would be required to increase their capability for product diversification. Regardless of market signals, because little additional cost is involved in recording lactose percentage in Australia, having information on 


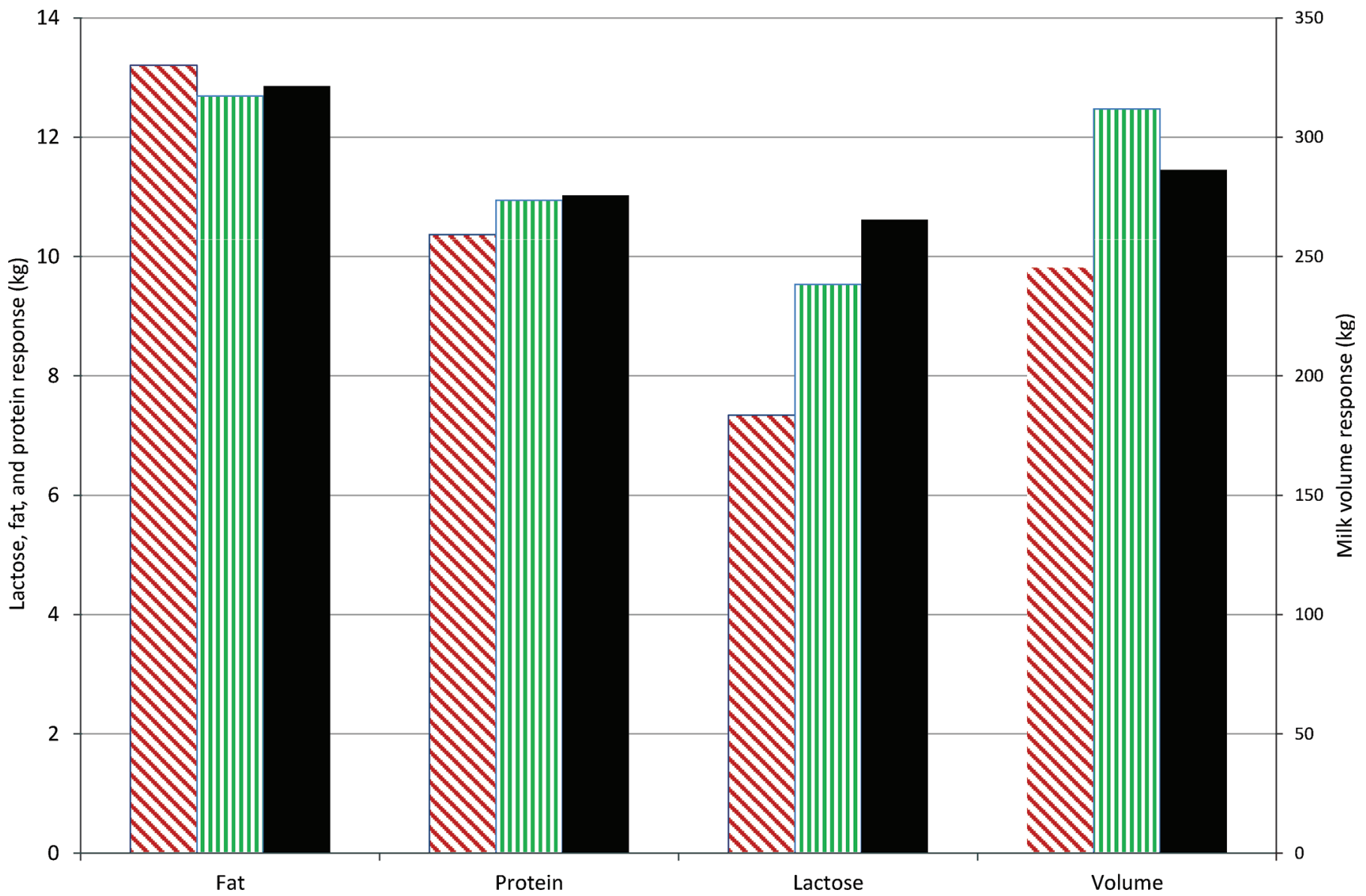

Figure 7. Responses to selection in milk, fat, protein, and lactose when the economic value (EV) on milk volume (MV) is $-\$ 0.1$ (diagonal stripes) or $\$ 0$ (vertical stripes) and the EV on lactose is $\$ 1.0$ and the EV on MV is $-\$ 0.1$ (solid black) and the EV for fat and protein are $\$ 1.79$ and $\$ 6.92$, respectively. Color version available online.

this trait is still worthwhile. Accumulating information on lactose percentage in the national database can enable the industry to respond quickly to future changes in the value of milk components.

\section{CONCLUSIONS}

The heritability of lactose percentage (0.25 to 0.37 ) was higher than lactose yield (0.11 to 0.20$)$ in the first parity. Genetically, the correlation of lactose percentage with protein percentage varied from 0.3 at the beginning to -0.24 at the end of lactation in the first parity. A similar change in the genetic correlations was also observed in the second and third parity. At all levels (i.e., genetic, environmental) the correlation between milk yield and lactose yield was close to 1 . The genetic and permanent environmental correlations between lactose percentage and SCC were stronger in the second and third parity and toward the end of the lactation $(-0.5)$ than in the first parity $(-0.1)$. The genetic cor- relation between lactose percentage in the first $120 \mathrm{~d}$ and CIV $(-0.23)$ was similar to correlation of CIV with protein percentage $(-0.28)$. The correlation of EBV of lactose percentage and EBV on traits such as survival, fertility, SCC, and angularity suggested that the value of lactose percentage as a predictor of fitness traits is weak. Currently, our results suggest that the benefit of including lactose yield or percentage into the breeding goal in overall Australian dairy production systems is limited. However, recording lactose percentage as the part of the routine milk recording system will enable the Australian dairy industry to quickly respond to any future change.

\section{ACKNOWLEDGMENTS}

The data were extracted from the Australian Dairy Herd Improvement Scheme database. We thank Kevin Beard (ADHIS, Melbourne, Australia) for his help with data extraction. The authors acknowledge financial 
support from the Australian Government (Department of Agriculture and Water Resources, Canberra) Rural R\&D for Profit Programme (MIRprofit) and Dairy Futures Cooperative Research Centre, Melbourne, Australia.

\section{REFERENCES}

ADHIS (Australian Dairy Herd Improvement Scheme). 2004. ABV Handbook Cows N Genes Workshop Manual, Melbourne, Australia.

Auldist, M. J., S. Coats, G. L. Rogers, and G. H. McDowell. 1995 Changes in the composition of milk from healthy and mastitic dairy cows during the lactation cycle. Aust. J. Exp. Agric. 35:427436.

Berry, D. P. 2015. Breeding the dairy cow of the future: What do we need? Anim. Prod. Sci. 55:823-837.

Bowman, P. J., P. M. Visscher, and M. E. Goddard. 1996. Customized selection indices for dairy bulls in Australia. Anim. Sci. 62:393403.

Buckley, F., K. O'Sullivan, J. F. Mee, R. D. Evans, and P. Dillon. 2003. Relationships among milk yield, body condition, cow weight, and reproduction in spring-calved Holstein-Friesians. J. Dairy Sci. 86:2308-2319.

Byrne, T. J., B. F. S. Santos, P. R. Amer, D. Martin-Collado, J. E. Pryce, and M. Axford. 2016. New breeding objectives and selection indices for the Australian dairy industry. J. Dairy Sci. 99:81468167.

CRV. 2017. Statistical Indicators. Accessed Jan 2016. https://www. crv4all-international.com/wp-content/uploads/2016/03/E-20NVI.pdf.

Dairy Australia. 2016. Production summary. Accessed Jun. 2016. http://www.dairyaustralia.com.au/Markets-and-statistics / Production-and-sales/Production-Summary.aspx.

Francisco, C. C., L. J. Spicer, and M. E. Payton. 2003. Predicting cholesterol, progesterone, and days to ovulation using postpartum metabolic and endocrine measures. J. Dairy Sci. 86:2852-2863.

Geary, U., N. Lopez-Villalobos, D. J. Garrick, and L. Shalloo. 2010. Development and application of a processing model for the Irish dairy industry. J. Dairy Sci. 93:5091-5100.

Gilmour, A. R., B. J. Gogel, B. R. Cullis, and R. Thompson. 2009. ASReml User Guide Release 3.0 VSN International Ltd., Hemel Hempstead, UK.

Haile-Mariam, M., P. J. Bowman, and J. E. Pryce. 2013. Genetic analysis of fertility and predictor traits in Holstein herds with low and high mean calving intervals, and in Jersey. J. Dairy Sci. 96:655-667.

Haile-Mariam, M., and M. E. Goddard. 2008. Genetic and phenotypic parameters of lactations longer than 305 days (extended lactations). Animal 2:325-335.

Harmon, R. J. 1994. Physiology of mastitis and factors affecting somatic cell counts. J. Dairy Sci. 77:2103-2112.
Lush, J. L. 1945. Animal Breeding Plans (3rd), Iowa State University Press, Ames.

Miglior, F., A. Sewalem, J. Jamrozik, J. Bohmanova, D. M. Lefebvre, and R. K. Moore. 2007. Genetic analysis of milk urea nitrogen and lactose and their relationships with other production traits in Canadian Holstein cattle. J. Dairy Sci. 90:2468-2479.

Miglior, F., A. Sewalem, J. Jamrozik, D. M. Lefebvre, and R. K. Moore. 2006. Analysis of milk urea nitrogen and lactose and their effect on longevity in Canadian dairy cattle. J. Dairy Sci. 89:4886-4894.

Morton, J. M., M. J. Auldist, M. L. Douglas, and K. L. Macmillan. 2016. Associations between milk protein concentration, milk yield, and reproductive performance in dairy cows. J. Dairy Sci. https:// doi.org/10.3168/jds.2016-11276.

Park, Y. K., H. C. Koo, S. H. Kim, S. Y. Hwang, W. K. Jung, J. M. Kim, S. Shin, R. T. Kim, and Y. H. Park. 2007. The analysis of milk components and pathogenic bacteria isolated from bovine raw milk in Korea. J. Dairy Sci. 90:5405-5414.

Ptak, E. P. B., and J. Bieniek. 2012. Genetic parameters for lactose percentage in the milk of Polish Holstein-Friesians. J. Anim. Feed Sci. 21:251-262

Reist, M., D. Erdin, D. von Euw, K. Tschuemperlin, H. Leuenberger, Y. Chilliard, H. M. Hammon, C. Morel, C. Philipona, Y. Zbinden, N. Kuenzi, and J. W. Blum. 2002. Estimation of energy balance at the individual and herd level using blood and milk traits in highyielding dairy cows. J. Dairy Sci. 85:3314-3327.

Reksen, O., Ø. Havrevoll, Y. T. Gröhn, T. Bolstad, A. Waldmann, and E. Ropstad. 2002. Relationships among body condition score, milk constituents, and postpartum luteal function in Norwegian dairy cows. J. Dairy Sci. 85:1406-1415.

Shuster, D. E., R. J. Harmon, J. A. Jackson, and R. W. Hemken. 1991 Suppression of milk production during endotoxin-induced mastitis. J. Dairy Sci. 74:3763-3774.

Sneddon, N. W. 2016. A genetic and economic evaluation of lactose in the New Zealand dairy industry. PhD Thesis. Massey University, Palmerston North, New Zealand.

Sneddon, N. W., N. Lopez-Villalobos, S. R. Davis, R. E. Hickson, and L. Shalloo. 2015. Genetic parameters for milk components including lactose from test day records in the New Zealand dairy herd. N. Z. J. Agric. Res. 58:97-107.

Sneddon, N. W., N. Lopez-Villalobos, R. E. Hickson, and L. Shalloo. 2013. Review of milk payment systems to identify the component value of lactose. Proc. N.Z. Soc. Anim. Prod. 73:33-36.

Stoop, W. M., H. Bovenhuis, J. M. L. Heck, and J. A. M. van Arendonk. 2009. Effect of lactation stage and energy status on milk fat composition of Holstein-Friesian cows. J. Dairy Sci. 92:1469-1478.

Stoop, W. M., H. Bovenhuis, and J. A. M. van Arendonk. 2007. Genetic parameters for milk urea nitrogen in relation to milk production traits. J. Dairy Sci. 90:1981-1986.

Stoop, W. M., J. A. M. van Arendonk, J. M. L. Heck, H. J. F. van Valenberg, and H. Bovenhuis. 2008. Genetic parameters for major milk fatty acids and milk production traits of Dutch Holstein Friesians. J. Dairy Sci. 91:385-394.

Welper, R. D., and A. E. Freeman. 1992. Genetic parameters for yield traits of Holsteins, including lactose and somatic cell score. J. Dairy Sci. 75:1342-1348. 